\title{
Measuring Farm-level Technical Efficiency of Urban Agriculture in Tanzanian Towns: The Policy Implications
}

\author{
Kizito K. Mwajombe ${ }^{1} \&$ Malongo R. S. Mlozi ${ }^{1}$ \\ ${ }^{1}$ Department of Agricultural Education and Extension, Sokoine University of Agriculture, Morogoro, Tanzania \\ Correspondence: Malongo R. S. Mlozi, Department of Agricultural Education and Extension, Sokoine University of \\ Agriculture, P.O Box 3002, Morogoro, Tanzania. Tel: 255-787-022-609. E-mail: mrsmlozi@yahoo.com
}

Received: November 26, $2014 \quad$ Accepted: December 29, $2014 \quad$ Online Published: January 9, 2015

doi:10.5430/wjss.v2n1p62 URL: http://dx.doi.org/10.5430/wjss.v2n1p62

\begin{abstract}
Technical Efficiency Indices of Urban Agriculture (UA) were determined using the stochastic frontier production function which incorporates a model of technical inefficiency effects. In 2010, farm-level data of 270 urban agriculture farmers in Tanzanian urban wards of towns of Arusha, Dar es Salaam and Dodoma was obtained using semi-structured questionnaires. The parameters were estimated simultaneously with those of the model of inefficiency effects. Using the maximum likelihood estimation technique, asymptotic parameter estimates were evaluated to describe efficiency determinants. Study results revealed that a mean technical efficiency index (TEI) of 0.72 was achieved implying that output from urban agriculture production could be increased by $28 \%$ using available technologies. Despite of urban farmers having entrepreneurial acumen, they faced several challenges in resource allocation. Land size, total variable costs, and extension service charges negatively impacted on TEI. The study recommends that the government using urban agriculture and livestock extension agents should explore profitable levels for promoting UA enterprises to ascertain profitable TEI levels and UA units.
\end{abstract}

Keywords: urban agriculture, technical efficiency index, urban agriculture and livestock extension agents, resource allocation, UA units

\section{Introduction}

Generally, most people believe that farming is an activity that should occur almost entirely in rural areas, but with growing economic austerity urban areas too have taken up serious agriculture involving crop cultivation and livestock keeping. Of recent farming has increasingly become a normal activity by most urban dwellers in an effort to address food insecurity, economic austerity, social problems and environmental degradation in their communities (Mougeot, 1994). United Nations Development Programme (UNDP) supports urban agriculture (UA) as an appropriate sustainable urban land management, food supply and security, and ecologically friendly practice (UNDP, 1996). Determining Technical Efficiency Index (TEI) of UA is central for selection of profitable UA units. Studies on potentials of UA in Tanzanian towns conducted by Sawio (1998), and Mlozi (1994; 1996) indicated that UA is gaining momentum and supported by the government and other institutions. Studies done in African towns and cities (Foeken et al., 2004; Mbiba, 1996; Mlozi et al., 2013; Owuor, 2006) show that as urban population swell due internal births and external immigrations also urban agriculture gains momentum on a transient trend - usually moving away from the densely built-up to areas with land and other necessary resources for its survival.

From the economic point of view, economic values of production hypotheses support the view that UA is a rational and a useful profitable activity in urban areas. von Thuneun theory of spatial location (Barlowe, 1978) show that there is an economic rationality on land use around a central market place. UA land use patterns are assumed to follow von Thuneun's model as perishable products such as vegetables and milk are produced close to city centres (Smith \& Olakoku, 1998). According to Kekana (2006) land should be zoned based on an economic rational land use for different enterprises including UA. Also, the three alternative economic theories (profit maximizing theories, utility maximization theories, and the risk averse) are important for understanding urban farmers' production choices and efficient behaviour. However, profit maximization has both a behavioural content (motivation of the household) and a technical economic content (economic performance of the farm as a business enterprise). Most economic theories address farm households as Decision Making Units (DMU) which are concerned with several questions. It is 
assumed that DMUs, in the short run will increase the amount of variable inputs as long as the additional revenue exceeds the additional costs sources. As such UA farmers would not produce at all if the price of an input exceeded the maximum average value of a product.

Prospects of getting high incomes induce UA farmers to produce more and adopt the recommended agricultural technologies. Hence, we can measure the Technical Efficiency (TE), which is the ability of a firm or enterprise to obtain the best production from a given set of inputs (output-increasing oriented), or the ability to use the minimum feasible amount of inputs given a level of output (input-saving oriented) (Green, 1980; Atkinson and Cornwell, 1994). An UA farmer in Tanzanian towns/cities is faced with a number of constraints that hinder her/his efficient production.

\subsection{Measuring Efficiency in Farming and UA}

Efficiency in farm production is a way to ensure that products are produced in the best and most profitable way using a given level of output with minimum quantity of inputs under a given technology. Maximum efficiency of a firm is attained when it becomes impossible to reshuffle a given resource combination without decreasing the total output. UA farmers aim to maximise household welfare, given household resources, prices and access to needed foodstuffs, inputs and risks and uncertainty about markets, policies and weather. Interviews with urban farmers (from several case studies) reveal that the kind of behavioural and economic incentives facing the household vary, even within the same city and culture (Nugent, 2000).

A study on efficiency (technical and allocative efficiency) on a sample of New England dairy farms using the stochastic frontier approach (SFA) and a Cobb-Douglas production function, found an overall economic inefficiencies of an average $30 \%$. However, the study revealed little difference between mean technical efficiency of $83 \%$ and mean allocative efficiency of $84.6 \%$ (Bravo-Ureta and Rierger, 1991). A study by Lansink et al. (2002) on technical efficiency of Finnish farms, using the data envelopment analysis (DEA) found that the livestock farms had technical efficiency scores of $69 \%$. However, as commented by Coelli et al. (2002), the efficiency indices obtained by different methods only measure the relative efficiency within the sample. For example, Bravo-Ureta and Rierger, (1991) found that farm size was a parameter, which revealed to have a significant influence on efficiency, Bailey et al. (1989), estimated technical, allocative and economic efficiency on a sample of Ecuadorian dairy farms, also found a positive relationship between farm size and technical efficiency. In contrast to the New England study, medium-sized Ecuadorian farms were found to be as allocatively efficient as large farms (Bailey et al., 1989).

Although various studies have examined the issues of productivity and technical efficiency of farmers, only a handful of them dwell on Sub-Saharan Africa (SSA) and only one was in Tanzania by Msuya \& Ashimogo (2006). Of the few studies that have analyzed efficiency in SSA agriculture include those of Shapiro and Muller (1977), Seyoum et al. (1998), Okike (2000), Udoh (2000), and Tchale and Sauer (2007). Several studies on efficiency have been carried out in Nigeria like those of Udoh (2000), Okike (2000), and Amaza (2000). Udoh employed the Maximum Likelihood Estimation (MLE) of the stochastic production function to examine the land management and resource use efficiency in South-Eastern Nigeria. The study revealed a mean output-oriented technical efficiency of 0.77 for the farmers, 0.98 for the most efficient farmers and 0.01 for the least efficient farmers. The study by Amaza investigated crop-livestock interaction and economic efficiency of farmers in the savannah zones of Nigeria. The study found that average economic efficiency of farmers was highest in the low-population-low market domain and crop-based mixed farming system.

The two most popular techniques used to measure farm efficiency are the DEA and the SFA (Charmes et al., 1978; Coelli \& Battese, 1996). DEA uses mathematical linear programming methods, whereas the latter uses econometric methods. The choice of method to use is in no way evident, but has to be decided in every case. However, DEA is a deterministic approach, meaning that it doesn't account for noise in the data. The SFA on the other hand, accounts for random errors and has the advantage of making inference possible (Coelli \& Battese, 1996). However, SFA is sensitive to the choice of functional form. In agriculture, an example is Iraizoz et al. (2003) who compared technical efficiency results on a sample of Spanish vegetable producers, and found correlation between the parametric and nonparametric approach.

UA in Tanzanian towns and cities is operated in three main areas namely high-density areas which have high concentration of people and houses and have smaller plot sizes; medium-density areas with relatively spacious plots, few people; and low-density areas with bigger plot sizes and less concentration of people. In these areas, there are a number of factors that influence performance and efficiency of UA activities. Some of these include socio-economic characteristics, land, labour, farm characteristics, institutional support, and presence of UA products marketed to urban dwellers. Yet other factors include presence of agricultural and livestock extension agents and availability of 
agriculture-and livestock-related inputs. Therefore, proper selections of the UA practice appear to influence the overall production efficiency.

\section{Methodological Approach}

\subsection{Description of the Study Areas}

Data for this study was collected from 270 respondents in three municipalities. The three municipalities were purposively selected: Arusha municipal council (AMC), Dodoma municipal council (DMC), and Kinondoni municipal council (KMC). KMC is in Dar es Salaam region and was selected because it lies at the coast of Indian ocean (10 metres asl). It has a burgeoning economy and UA activities have flourished since the 1970s, especially livestock keeping. Of the 5 million estimated human population of Dar es Salaam region in 2013, about a third (1.6 mil.) live in KMC. The main economic activities in KMC include trade, formal employment, petty trading and UA activities. KMC has hot humid climate with two rain seasons in a year: the short rain season occurs between October and December, and the long rain season from March to May. On average, $\mathrm{KMC}$ receives about 1,100 mm. of rainfall per annum with mean temperatures of $26^{\circ} \mathrm{C}$ ranging from 30 to $60^{\circ} \mathrm{C}$. Administratively, $\mathrm{KMC}$ is composed of three divisions, 27 wards and has 113 urban mitaa (mtaa is singular in Kiswahili for a street).

AMC is located in the northern part of Tanzania about 650 kilometres away from Dar es Salaam. The city was selected because of its vibrant tourist attraction which has increased demands for fresh foods and hence increased UA activities. The municipality is situated in northern Tanzania surrounded by some of Africa's most famous landscapes and national parks. Despite its proximity to the Equator, Arusha's elevation of $1400 \mathrm{~m}$ keeps temperatures down and alleviates humidity. Temperatures range between 13 to $30^{\circ} \mathrm{C}$ with mean temperature of $25^{\circ} \mathrm{C}$. It has distinct wet and dry seasons with bimodal rainfall patterns: short rains from October to December; and long rains from March to May.

DMC is located in the centre of country 468 kilometres west of the former capital city of Dar es Salaam. It covers a total area of 2,669 square kilometres of which 625 square kilometres are urbanised. It has semi-arid climatic conditions, receiving about $570 \mathrm{~mm}$ of rainfall per annum with temperatures ranging from 16 to $36^{\circ} \mathrm{C}$ with mean temperatures of $29^{\circ} \mathrm{C}$. DMC, on the other hand, was selected because it is a designate national capital city and here too UA flourishes to feed the increasing human population. In all three studied municipalities, main UA activities include crop-based (amaranths, plantains, cabbages) and livestock keeping (dairy cattle, broilers, layers); ornamental plants (trees, flowers). However, this study investigated vegetable growing and livestock keeping.

\subsection{Sampling Frame and Sampling Procedures}

The study adopted a cross-sectional approach. Hence the sampling frame included all urban farmers keeping dairy cattle, broilers and layers and growing vegetables in the three study municipalities. The study elicited information from 270 small-scale respondents--urban farmers undertaking urban agriculture in study municipalities. At household level, the UA enterprise managers were interviewed and provided UA enterprise information, especially on agricultural input use and production technologies used in low-, medium-, and high-density areas. Urban farmers were stratified according to their dominant UA enterprises. Later, a simple random sampling was used to get UA farmers in each of the dominant UA enterprise to ensure that each UA farmer had an equal chance of being included in the study sample. For comparison purposes, UA farmers (respondents) undertaking vegetable-based activities (amaranths, plantains, cabbages) and livestock-based activities (dairy keeping, broilers, layers) were investigated.

\subsection{Pre-testing of Instruments}

The developed questionnaire was pre-tested by administering it to a sample of 20 randomly selected UA farmers in Mabibo ward in Kinondoni municipality in Dar es Salaam region. This was to ascertain the reliability of the instrument. Data collected during pre-testing was analyzed to obtain correlation coefficients of the answers. A reliability coefficient of 0.8 was attained, which was higher than 0.7 recommended by Norland (1990) and Radhakrishna et al. (2003). Thereafter, corrections were made as suggested during the exercise on the wording of questions and their order, and respondents from Mabibo were not included in the main study. Validation of the questionnaire was done by giving it to six experts in the Department.

\subsection{Primary and Secondary Data Collection}

Primary data was collected from respondents using questionnaires. Information collected included land size, number of UA units, production levels, labour sources and types. Other information was on charges that respondents paid to agriculture/livestock extension agents, production variable costs and incomes received. This information was used to 
determine UA farm level technical efficiencies of the individual DMUs.

\subsection{Data Processing and Analysis}

Data from the primary sources was verified, coded and analyzed using different qualitative and quantitative statistical softwares including the Statistical Package for Social Sciences (SPSS) and a computer programme for Stochastic Frontier Production and Cost Function Estimation (FRONTIER Version 4.1). The purpose was to explain the phenomena and detect any associations between the variables for making inference about UA practices and efficiency in Tanzanian cities. Descriptive statistics were used for comparison purposes on variables of interest to explain phenomena. Additionally, standard deviations, standard errors were used to summarize variations between UA practices. Chi-square test was employed to determine variations between municipalities on various attributes related to UA. The frontier productivity analysis was employed to underscore the likely efficiency of individual urban farmers as Decision Making Units (DMUs) and these efficiency scores were plotted to produce Frontier Production Function (FPF) curve. Tobit regression was employed to model the technical inefficiency as a function of the individual farmer's inherent characteristics.

\subsection{Efficiency of UA Enterprises}

Efficiency is an important economic concept used in assessing producers' performance to ensure that products are produced in the best and most profitable way (Park et al., 2010). Agricultural eco-efficiency is promoted as resources of increasing main production and recuperating food security (Jansen, 2000). Analysis of UA production efficiency is an important aspect to prevent waste of resources as its activities are carried out under constrained resource base and space within municipalities. This study examined the technical efficiency (TE) of UA activities in three municipalities. TE here refers to the ability of the UA farmer to produce maximum output using a given level of agricultural inputs.

Primary data in this study was mainly obtained from UA farmers in three municipalities using a semi-structured questionnaire. Later the study utilised stochastic production frontier, which builds hypothesized efficiency determinants into inefficiency error components (Coelli \& Battese, 1996). The measure of output is the total monetary value of UA products obtained during the last season (in Tanzanian shillings). And the agricultural inputs included size of land in square metres, family labour (in man days per day), hired labour (in man days per day), total variable cost for last season excluding charges for services offered by urban agriculture and livestock extension agents (UALEAs) (in Tanzanian Shillings), and charges paid to UALEAs for extension services received (in Tanzanian shillings).

\subsection{Model Specification and Empirical Stochastic Frontier Model}

The aim of this study was to establish UA technical efficiency in three municipalities. Hence, an appropriate model specification was used in two steps. The choice of a functional form in an empirical study is of prime importance, since the functional form can significantly affect the results. A flexible functional form is generally preferred, since it does not impose general restrictions on the parameters nor on the technical relationships among inputs. In this study, Cobb-Douglas production function is selected to make the distributional assumptions consistent with functional form. The analysis was carried out as specified in the following two steps.

\subsubsection{Step One}

As a first stage in the efficiency analysis, Ordinary Least Square (OLS) estimation is made on Cobb-Douglas production function. However, Cobb-Douglas production function has some limitations in a way that it doesn't directly reflect relationship between input and output base and assumes a production status in a static time point. Based on the significance of the parameter estimates, information will be gained on which variables should be included in the stochastic frontier analysis. The OLS is based on stochastic frontier model as proposed by Coelli \& Battese (1996) that enterprise effects are assumed to be distributed as a truncated normal random variable, in which the inefficiency effects are directly influenced by a number of variables. Based on the study objectives, the choice of the variables was made because these inputs are the conventional inputs used in UA in the study areas. The model is given as:

$$
\operatorname{Ln} Y i=\beta o+\Sigma i \beta i \ln X i j+\varepsilon I
$$

Where $Y_{i}=U A$ output in Tanzanian Shillings, $X_{1 j}=$ Family labour used in man days, $X_{2 j}=$ Hired labour utilized measured in mandays, $X_{3 j}=$ land area under UA (Sq. metres), $X_{4 j}=$, Total variable costs for UA enterprise measured in Tanzanian shillings $X_{5 j}=$ Extension charges measured in Tanzanian shillings, $l n=$ Natural logarithm, $i=1 \ldots n$, $\mathrm{n}=270$. 


\subsubsection{Step Owo}

After getting necessary information about the inclusion of variables for the frontier analysis, the empirical version of the stochastic frontier model is then given as:

$$
\operatorname{Ln} Y_{i}=\beta_{o}+\Sigma_{i} \beta_{i} \ln X_{i j}+\varepsilon_{I}
$$

Where the variables $\mathrm{X}_{\mathrm{ij}}$ are the variables selected based on OLS estimation in the first step.

The error term $\left(\varepsilon_{I}\right)$ is now defined as:

$$
\varepsilon_{\mathrm{I}}=\mathrm{Vi}-U_{i}
$$

$$
\mathrm{i}=1 \ldots \mathrm{n}, \mathrm{n}=270 .
$$

The systemic error component $V_{i}$, which captures the random variation in output due to factors outside the control of the UA farmer, are assumed to be independently and identically distributed as $V_{i} \sim i i d \mathrm{~N}\left(0, \delta_{\mathrm{v}}{ }^{2}\right)$, independently of $U_{i}$ which measures the technical efficiency relative to the stochastic frontier. Based on the assumption that $V_{i}$ and $U_{i}$ are independent, the parameters of the production frontier (equation 1) will be estimated using maximum likelihood method. Four distributional assumptions, half-normal, truncated-normal, exponential and gamma distributions, will be made on the distribution of $U_{i}$. As one of the main objective of this study, effects of distributional assumptions on the technical efficiency levels of each UA enterprise representing a UA farmer as a DMU were investigated and compared empirically. DMU specific technical efficiency representing maximum possible output $\left(\mathrm{Y}^{*}\right)$ was expressed as:

$$
\mathrm{Y}_{\mathrm{i}}^{*}=\mathrm{f}\left(\mathrm{X}_{\mathrm{i}} ; \beta\right) \exp \left(V_{i}\right)
$$

Equation (4) can be re-written as $\mathrm{Y}_{\mathrm{i}}=\mathrm{Y}_{\mathrm{i}}{ }^{*} \exp \left(-U_{i}\right)$

Therefore, the efficiency of the $\mathrm{i}^{\text {th }}$ individual UA enterprise, denoted by $T E_{\mathrm{i}}$, was given by;

$$
\mathrm{TEi},=\mathrm{Y}_{\mathrm{i}} / \mathrm{Y}_{\mathrm{i}}^{*}=\exp \left(-\mathrm{U}_{\mathrm{i}}\right)
$$

\subsection{Sources of Inefficiency}

Knowing that the UA enterprise is inefficient might not be useful unless the sources of inefficiency are examined. The source of efficiency differential that is observed among DMUs is an issue of overriding concern. According to Kumbhakar \& Bhattacharya (1992) socio-economic factors, demographic factors, farm characteristics, environmental and non-physical factors pose effects on efficiency of an enterprise. Therefore, sources of inefficiency differentials that are observed among UA farmers and are issues of concern. For the purpose of this study the second stage of analysis involved assessing UA farmers' characteristics and their magnitude of influence on the overall efficiency in UA enterprises by calculating likelihood estimates.

The expected relationship of UA farmer's characteristics and TE are mixed. For instance, OWNER is a binary variable that is included to estimate the impact of the sex of the enterprise manager. Most commercial UA enterprises in the study areas were managed by females for two main reasons. Firstly, if a husband was dead or if alive was transferred to work in another station. Secondly, if a married woman had quit formal employment and decided to manage other household enterprises including UA. Therefore, female managed UA enterprises would have better performance as the wife would have a better opportunity to offer close follow-up and supervision of UA activities. For these reasons, the expected sign for this variable in the model is positive.

The variable education (EDUC) the number of years of schooling achieved by the UA enterprise manager is used as a proxy for managerial input. High level of educational achievement may lead to better assessment of the importance and complexities of making good farming decisions, including efficient use of inputs. The expected sign for education variable is positive. YUA represent the number of years a farmer was actively involved in UA activities. This variable is aimed at capturing the farming experiences one had. Based on challenges that one come across, and solved them and continued with UA it is assumed that one has accumulated experiences to run UA enterprises. The expected sign for YUA variable is positive. EXTSER represents a binary variable that is included to estimate the impact of agricultural/livestock extension services availability on technical efficiency level of UA enterprise. Most commercial UA enterprises in the study sites that earned higher returns attracted UALEAs to visit and give advice. However, such visits could have both positive and negative influence on the technical efficiency levels. The first one is if the EXTSER charges were excessively high they could impact on total returns of the UA farmer. On the other hand, they could positively assist the farmer to acquire more technologies for undertaking UA activities. Such efforts could increase returns for the enterprise. Hence, the expected sign for EXTSER is either negative or positive.

CREDIT represents a binary variable that is included to estimate the impact of CREDIT provision to support UA 
activities. Most commercial UA enterprises in the study areas that had more returns were expected to receive credit. Credit availability is expected to positively increase investment and hence positively influence the technical efficiency level of the UA enterprise. The expected sign for CREDIT is positive. ADENSITY refers to a location where the UA enterprise is undertake ( $1=$ low-density; $2=$ medium-density; $3=$ high-density). Depending on the plot description given in each municipality, all low-density areas were found to be spacious and comfortably accommodated UA activities. Hence, undertaking UA in high-density areas could create more challenges (like problems of manure disposal, water scarcity etc.) which could negatively impact on technical efficiency levels of an UA farmer. The expected sign for ADENSITY variable is negative.

In this study, the following model is used to underscore determinants of DMU specific technical efficiency. The level of efficiency lies between 0 and 1 . The model is specified as:

$$
\mathrm{TE}=\mathrm{b}_{1} \text { OWNER }+\mathrm{b}_{2} \text { EDUC }+\mathrm{b}_{3} \text { YUA }+\mathrm{b}_{4} \text { EXTSER }+\mathrm{b}_{5} \text { CREDIT }+\mathrm{b}_{6} \text { ADENSITY }+\varepsilon_{\mathrm{i}}
$$

Where:

$\mathrm{TE}=$ level of technical efficiency obtained from equation 6

$b_{i}(i=1 \ldots$ are coefficients (inefficiency parameters to be estimated)

OWNER $=$ Dummy $(1$ for female and 0 male $) ;$ EDUC $=$ Number of years of schooling achieved by UA farmer; YUA $=$ Number of years actively involved in UA to capture experience in UA; EXTSER $=$ Extension services support for UA (dummy 1 for availability, 0 otherwise); CREDIT = Dummy ( 1 if a farmer has obtained credit for UA, 0 for otherwise); ADENSITY = Area density under which UA is performed; $\varepsilon=$ error term that follows a truncated normal distribution. The expected signs for these variables are shown in Table 1 below.

Table 1. Expected signs of independent variables.

\begin{tabular}{|l|l|}
\hline Variable & Expected sign \\
\hline OWNER & + \\
\hline EDUC & + \\
\hline YUA & + \\
\hline EXTSER & + or - \\
\hline CREDIT & + \\
\hline ADENSITY & - \\
\hline
\end{tabular}

\section{Findings and Discussions}

\subsection{Estimates of Stochastic Frontier Production Function in UA}

To estimate TE in UA, the Maximum Likelihood (ML) method using FRONTIER 4.1 software developed by Coelli et al. (2002) was adopted for UA activities as presented in Table 2. From the study findings all except the family labour variable had positive signs suggesting that more output would be obtained from the use of additional quantities of these variables, ceteris paribus. The coefficient of land size for UA was positive and statistically significant at $p \leq 0.005$. The statistical significance of the variable explains the importance of land in UA activities, meaning that its shortage would not only pose a negative effect on UA production, but an indirect negative effect on output through reducing the marginal productivity of non-land inputs. Similar findings were reported by Okike (2000) in the savannah areas of Nigeria, Umoh (2006), and Shehu et al. (2007) in Adamawa state, Nigeria who found that small land size had a significant effect on agriculture production. This indicates that smaller land sizes for UA highly influenced production efficiency, especially for UA practices requiring larger areas like dairy cattle keeping. However, UA activities like poultry keeping could be accommodated on smaller plot sizes.

The production elasticity of output with respect to family labour ( $\left.\beta_{2}\right)$ (man days per day) had a negative sign of -0.36 and was not statistically significant at $\mathrm{p} \leq 0.10$. The negative sign however, could explain the reliance on family labour for reducing production costs. However, dependency on hired labour would improve efficiency in UA production as shown by the positive sign of hired labour $\left(\beta_{3}\right)$ coefficient of 0.17 indicating its positive relationship with UA efficiency, and the hired labour variable was found not to be statistically significant at $p \leq 0.10$. However, increasing hired labour by 10 percent would only result into increase in UA output by approximately two percent 
only. The coefficient for total variable costs incurred $\left(\beta_{4}\right)$ in UA activities was positive, but and was statistically significantly different at $\mathrm{p} \leq 0.015$ (Table 2). However, the positive sign of total variable cost is an indication of association to increasing production levels in UA, and it is the determinant of how much is incurred to run UA activities on daily basis. This means that the rate at which the daily UA enterprise requirements are met, the higher the efficiency in undertaking it.

Table 2. Maximum Likelihood estimates of the stochastic frontier function and TE

\begin{tabular}{|l|l|l|l|l|l|}
\hline Variable & Parameter & Co-efficient & Standard error & t-statistic & p-value \\
\hline Constant & $\beta_{0}$ & 0.118 & 0.22 & 1.199 & $0.10^{\text {ns }}$ \\
Land size & $\beta_{1}$ & 0.152 & 0.89 & 2.312 & $0.005^{* *}$ \\
Family labour & $\beta_{2}$ & -0.356 & 0.97 & -0.464 & $0.10^{\text {ns }}$ \\
Hired labour & $\beta_{3}$ & 0.173 & 0.11 & 1.426 & $0.10^{\text {ns }}$ \\
Variable cost (Tshs) & $\beta_{4}$ & 0.509 & 0.13 & 2.117 & $0.015^{* *}$ \\
UALEAs charges (Tshs) & $\beta_{5}$ & 0.101 & 0.11 & 1.194 & $0.10^{\text {ns }}$ \\
\hline Sum of elasticity's & & 0.697 & & & \\
Sigma squared $\left(\delta^{2}\right)$ & & 0.823 & 0.35 & 1.649 & \\
Gamma $(\gamma)$ & & 0.942 & 0.43 & 1.113 & \\
Log likelihood & & -0.269 & & & \\
LR test & & 0.113 & & & \\
\hline
\end{tabular}

$* *=$ Statistically significant at $\mathrm{p} \leq 0.05$.

Similarly, UALEAs charges variable $\left(\beta_{5}\right)$ had a positive sign, however, was not statistically significant at $\mathrm{p} \leq 0.10$. The positive sign of this variable however, signified that the more an UA farmer received information and services form UALEAs the more efficient he/she became in running UA activities. Additionally, efficient UA farmers attracted UALEAs to visit them more frequently, which increased the UA farmer efficiency in running their UA activities (see Mlozi, 1994). The positive relationship of the signs on the input coefficients agrees with findings by Amaza and Olayemi (2000) in Gombe state in Nigeria, Amaza et al. (2005) in Chad basin development area - Nigeria, Ebong et al. (2009) in Akwa Ibom state - Nigeria, and Onyenweaku et al. (2005) in Nasarawa state - Nigeria. The positive relationship between input variables and TE of UA shows their importance in enhancing levels of UA production in Tanzanian municipalities.

The yield function was expressed as a Cobb-Douglas function; hence, the coefficients of variables were the direct elasticity. The elasticity included land for UA, hired labour, total variable costs and charges for extension services which were all positive. Total variable costs component appeared as the most important factor affecting UA production with an elasticity of 0.509 (Table 2). This implied that increasing expenses in total variable costs by 10 percent could lead to increasing UA output by 5 percent. Further, the study results show that more inputs are required in UA activities like supplementary feeds, animal medications, acaricides, fungicides, etc., which would greatly improve UA activities TE. These study results indicate that input allocation and use in UA activities in the study areas was still in the rational stage of production, that is, increasing their use would increase UA output. These results confirm findings of Umoh (2006) in Uyo metropolis, south-eastern Nigeria who found that positive relationship of variable costs (fertilizers, planting materials) increased TE UA vegetable output. Further, the estimated return-to-scale computed as the sum of the estimated output elasticity's was 0.697 , suggesting that UA farmers were operating in the decreasing returns to scale region (efficient stage). This implied that a unit increase to the quantities of the production inputs would lead to less than proportionate increase to the output of UA, ceteris paribus. That is, a unit increase in inputs will lead to increase in UA production, however, not at an equal rate as the input increase. However, these results are contrary to those by Idiong (2007) in Cross River state - Nigeria. The variance parameter $\delta^{2}$ (which is the model variance) was 0.94 , which shows the goodness of fit and correctness of the distributional form assumed for the composite error term. The gamma $\gamma$ indicate the systematic influences that are unexplained by production at 0.82 , which was found not to be statistically significant at $\mathrm{p} \leq 0.05$ (Table 2 ). This is an 
indication that $82 \%$ of variation in UA output was attributed to technical inefficiency in the resource use, meaning that the inefficiency effects had a significant contribution to the technical inefficiencies of UA farmers.

\section{Conclusion and Recommendation}

In Tanzania, UA takes place for economic and nutritional reasons, especially to the poor urban dwellers, and it is done irrationally. Hence, the main aim of this study was to establish UA technical efficiency in three municipalities. Hence, an appropriate model specification was used in two steps. In this study, OWNER was a binary variable to estimate the impact of the sex of the enterprise manager and had positive sign in the model. The variable education (EDUC) meant the number of years an UA farmer respondents attended school, and this was used as a proxy for managerial input. High level of educational achievement lead to better assessment of the importance and complexities of making good farming decisions, including efficient use of inputs. The expected sign for education variable was positive. YUA represented the number of years a farmer was actively involved in UA activities. This variable is aimed at capturing the farming experiences one had. Based on challenges that one come across, and solved them and continued with UA it is assumed that one has accumulated experiences to run UA enterprises. The expected sign for YUA variable is positive. EXTSER represented a binary variable that was included to estimate the impact of agricultural/livestock extension services availability on technical efficiency level of UA enterprise.

Most commercial UA enterprises in the study sites that earned higher returns attracted UALEAs to visit and give advice. However, such visits could have both positive and negative influences on the technical efficiency levels. Similarly, UALEAs charges variable $\left(\beta_{5}\right)$ had a positive sign, however, was not statistically significant $p \leq 0.10$. The positive sign of this variable however, signified that the more an UA farmer received information and services from UALEAs the more efficient he/she became in running UA activities. Additionally, efficient UA farmers attracted UALEAs to visit them more frequently. CREDIT represented a binary variable that is included to estimate the impact of CREDIT provision to support UA activities, and it had positive sign. ADENSITY refers to a location where the UA enterprise is undertake ( $1=$ low-density; $2=$ medium-density; $3=$ high-density), and it had negative sign.

The Maximum Likelihood (ML) method using FRONTIER 4.1 software developed by [27] was adopted to estimate TE for UA activities as presented in Table 2 above. The study results show that all except the family labour variable had positive signs suggesting that more output would be obtained from the use of additional quantities of these variables, ceteris paribus. The statistical significance of the variable explains the importance of land in UA activities, meaning that its shortage would not only pose a negative effect on UA production, but an indirect negative effect on output through reducing the marginal productivity of non-land inputs. Further, the study results indicated that smaller land sizes for UA highly influenced production efficiency, especially for UA practices requiring larger areas like dairy cattle keeping. However, UA activities like poultry keeping could be accommodated on smaller plot sizes. The production elasticity of output with respect to family labour $\left(\beta_{2}\right)$ (man days per day) had a negative sign. The negative sign however, could explain the reliance on more family labour for reducing production costs. However, the study results showed that dependency on hired labour would improve efficiency in UA production as shown by the positive sign of hired labour $\left(\beta_{3}\right)$ coefficient, although the variable was not statistically significant at $\mathrm{p} \leq 0.10$. Similarly, UALEAs charges variable $\left(\beta_{5}\right)$ had a positive sign, however, was not statistically significant at $\mathrm{p} \leq 0.10$. The positive sign of this variable however, signified that the more an UA farmer received information and services form UALEAs the more efficient he/she became in running UA activities. The positive relationship between input variables and TE of UA shows their importance in enhancing levels of UA production in Tanzanian municipalities.

Further, the study results show that more inputs are required in UA activities like supplementary feeds, animal medications, acaricides, and fungicides, among many others, which would greatly improve UA activities TE. These study results indicate that input allocation and use in UA activities in the study areas was still in the rational stage of production, that is, increasing their use would increase UA output. Further, the estimated return-to-scale computed as the sum of the estimated output elasticity's was 0.697 , suggesting that UA farmers were operating in the decreasing returns to scale region (efficient stage). This implied that a unit increase to the quantities of the production inputs would lead to less than proportionate increase to the output of UA, ceteris paribus. That is, a unit increase in inputs will lead to increase in UA production, however, not at an equal rate as the input increase. The study further found that combining different UA activities was possible and profitable, especially in low-medium density areas, and only if single UA activities were done in high-density areas.

In Tanzanian municipalities, UA activities provide additional earnings to individuals and families who are employed, unemployed, poorly paid, low- and middle-class urban dwellers, divorced, and widowed women and men. UA activities contribute to urban food security, especially for those who cannot pay for all of their food needs. Also, the 
activities narrow the food source gap between food stuffs supplied in municipalities and that from rural areas, given that the later are costly because they require elaborate handling, marketing, transportation, and distribution. And because of these and other reasons, UA activities in municipalities continue with municipal authorities' knowledge. Hence, policy implications for improving TE of UA activities in urban areas include the following recommendations.

Municipal agriculture and livestock extension officers (MALEOs) in the respective municipalities should educate UA farmers on improved ways of keeping livestock and growing vegetables for increasing their TE.

MALEOs in the respective municipalities should educate UA farmers so that the credit they get is used to buy agricultural and livestock inputs for improving productivity to attain high TE.

MALEOs in the respective municipalities should educate UA farmers in high-density areas not to undertake more than one UA enterprises as a combinations lead to low TE.

\section{Acknowledgements}

The authors wish to thank the financial assistance from the Norwegian Government through the PANTIL programme at Sokoine Univerity of Agriculture in Morogoro, Tanzania.

\section{References}

Amaza, P. S., \& Olayemi, J. K. (2000). The influence of education and extension contact on crop in Gombe state, Nigeria. Nig. J. of Agrib. and Rural Dev. 1, 80-92.

Amaza, P. S. (2000). Efficiency of food crop production in Gombo state, Nigeria. PhD Thesis, Ibadan University, Nigeria.

Amaza, P. S., Kwaghe, P. V., \& Ojo, N. (2005). Determinants of wheat production and technical efficiency in the Chad basin development area, Nigeria. Nig. J. of Agric. Food and Envt, 2, 1-6.

Atkinson, S. E., \& Cornwell, C. (1994). Estimation of output and input Technical Efficiency Using a Flexible Functional Form and panel data. Int. Econ. Review, 35(1), 245-255.

Bailey, D. V., Biswas, B., Kumbhakar, S. C., \& Schulthies, B. K. (1989). An analysis of technical, allocative and scale inefficiency: The case of Ecuadorian dairy farms. Western J. of Agric. Economics, 14, 30-37.

Bailey, K. D. (1994). Methods of Social Science Research ( $4^{\text {th }}$ ed.). The Free Press. A Division of Macmillan Inc. New York. p. 588.

Barlowe, R. (1978). Land Resource Economics. The economics of Real Estate ( $3^{\text {rd }}$ ed.).

Bravo-Ureta, B. E., \& Rieger, L. (1991). Dairy farm efficiency measurement using stochastic frontiers and neoclassical duality. American J. of Agric. Economics, 73, 421-428.

Charmes, A., Cooper, W. W., \& Rhodes, E. (1978). Measuring the efficiency of Decision Making Units. European J. of Operations Res, 2(6), 429-444.

Coelli, T., \& Battese, G. E. (1996). Identification of Factors which influence the technical inefficiency of Indian farmers. Austrian J. of Agric. Economics, 40, 103-128.

Coelli, T. J., Rehman, S., \& Tirtle, C. (2002). Technical allocative, cost and scale efficiencies in Bangladesh rice cultivation: A non-parametric approach. J.of Agric. Economics, 533, 607-626.

Ebong, V. O., Okoro, U. S., \& Effiong, E. O. (2009). Determinants of technical efficiency of urban farming in Uyo metropolis of Akwa Ibom state, Nigeria. J. of Agric. and Soc. Sci., 5(3):89-92.

Foeken, D., Sofer, M., \& Mlozi, M. (2004). Urban agriculture in Tanzania: Issues of sustainability. African Studies Centre, Research Report No. 75. Leiden, The Netherlands. p. 195.

Greene, W. H. (1980). On the Estimation of a Flexible Frontier Production Model. J. of Econometrics, 13(1), 101-115.

Idiong, I. C. (2007). Estimation of farm level technical efficiency in small-scale swamp rice production in cross river state of Nigeria. A stochastic Frontier Approach. World J. of Agric. Sci., 3(5), 653-658.

Iraizoz, B., M.Rapun, \& Zabaleta I. (2003). Assessing technical efficiency of horticultural production in Navarra, Spain. Agric. Syst., 78(3), 387-403. 
Jansen, L. (2000). "Quality of Life", sustainable and world-wide: New challenges for agricultural research: In: $A$. Boekestein, (ed). Towards and agenda for agricultural research in Europe. Proceedings of conference held in Wageningen, The Netherlands. pp. 227-237.

Kaufman, J., \& Bailkey, M. (2000). Farming Inside Cities: Entrepreneurial Urban Agriculture in the United States. Lincoln Institute of Land Policy Working Paper. Chicago, USA. p. 34.

Kekana, D. S. (2006). A socio-economic analysis of urban agriculture: The Soshanguve project case study. A Thesis submitted in partial fulfilment of the requirements for the Degree. Magister Institutional Agrariar. Department of Agricultural Economics, Extension and Rural Development. University of Pretoria. p. 83.

Kumbhakar, S. C., \& Bhattacharya, A. (1992). Price Distortion and Resource Use Efficiency in Indian Agriculture: A Restricted Profit Function Approach. J. of Rev. of Econ. and Stat., 74, 231-239.

Lansink, O. A., Pietola, K., \& Backman, S. (2002). Efficiency and productivity of conventional and organic farms in Finland 1994-1997. J. of European Rev. of Agric. Econ, 29(1), 51-65.

Mbiba, B. (1996). Urban agriculture in Zimbabwe, Avery, Ashgate Publishing Limited, Aldershot, UK, p. 220.

Mlozi, R. S. M., Lupala, A., Chenyambuga, S. W., Liwenga, E., \& Msogoya, T. (2013). Knowledge assessment on the effects of climate change due to keeping livestock in urban and peri-urban areas of Dar es Salaam, Tanzania. Intern. NGO J., 8(1), 1-12.

Mlozi, M. R. S. (1994). Inequitable agricultural extension services in the urban context: The case of Tanzania. In N.P. Stromquist (Ed.), Education in Urban Areas: Cross-national Dimensions. Praeger, Westport, USA. pp. 105-128.

Mlozi, M. R. S. (1996). Urban agriculture in Dar es Salaam: Its contribution to solving the economic crisis and the damage it does to the environment. Dev. So. Afr., 13(1), 47-65.

Mougeot, L. (1994). Urban food production: evolution, official support and significance. Cities Feeding People Report 8, 26. International Development Research Centre, Ottawa, ON, Canada.

Msuya, E., \& Ashimogo, G. C. (2006). An estimation of technical efficiency in Tanzanian sugarcane production: A case study of Mtibwa sugar company out grower's scheme. J. of Econ. Dev. Vol. 1, Mzumbe University, Tanzania.

Norland-Tiburg, E. V. (1990). Controlling error in evaluation instruments. J. of Ext., 28(2). Retrieved from http://www.joe.org.jpe/1990summer/\#2.html

Nugent, R. (2000). The impact of urban agriculture on the household and local economies. In Bakker, N; M. Dubbeling; S. Gender; U. Sabel Koschella; H de Zeeuw (eds), Growing cities, growing food, urban agriculture on policy agenda. DSE German, pp. 67-97.

Okike, I. (2000). Crop-livestock interaction and economic efficiency of farmers in the Savannah zone of Nigeria. $\mathrm{PhD}$ thesis, University of Ibadan, Nigeria.

Onyenweaku, C. E., Igwe, K. C., \& Mbanasor, J. A. (2005). Application of a stochastic frontier production functions to the measurement of technical efficiency in yam production, in Nasarawa state, Nigeria. J. of Sust. Trop. Agric. Res., 13, 20-25.

Owuor, S. O. (2006). Bridging the urban-rural divide: Multi-spatial livelihoods in Nakuru town, Kenya. African Studies Centre, Research Report No. 81. Leiden, The Netherlands. p. 274.

Park, S. E., Howden, S. M.., Crimp, S. J., Gaydon, D. S. Attwood, S. J., \& Kokie, P. N. (2010). More than Eco-efficiency is required to improve food security. Crop Sc., 50, 132-141.

Radhakrishna, R. B., Francisco, C. L., \& Baggett. C. D. (2003). An analysis of research designs used in agricultural and extension education. Proceedings of the $30^{\text {th }}$ National Agric. Educ. Res.

Sawio, C. J. (1998). Urban Agriculture in Dar es Salaam. A report presented for the Cities Feeding People workshop: "Lessons learned from urban agriculture projects in African cities, ” Nairobi, Kenya, June 21-25, 1998.

Seyoum, E. T., Battese, G. E., \& Fleming, E. M. (1998). Technical efficiency and productivity of maize producers in Eastern Ethiopia. A study of farmers within and outside the Sasakawa-Global 2000 Project. J. of Agric. Econ., 19, $341-348$.

Shapiro, K. H., \& Muller, J. (1977). Sources of technical efficiency: The role of modernization and information. J. of Econ. Dev. and Cult. Change, 25(2), 148-156. 
Shehu, J. F., Mshelia, S. I., \& Tashikalma, A. K. (2007). Analysis of technical efficiency of small-scale rain-fed upland rice farmers in North-west agricultural zone of Adamawa state, Nigeria. J. of Agric.and Soc. Sci, 3(4), 133-136.

Smith, O. B., \& Olaloku, E. A. (1998). Peri-urban Livestock Production Systems. Cities Feeding People Series, Report, No. 24, International Development Research Centre, Ottawa, ON, Canada.

Tchale, H., \& Sauer, J. (2007). The efficiency of maize farming in Malawi: A bootstrapped translog frontier. Cashiers D'economic et Sociologie Rurales, No. 82-83.

Udoh, E. J. (2000). Land management resource use efficiency among farmers in Southern Eastern Nigeria. PhD thesis, University of Ibadan, Nigeria. p. 280.

Umoh, G. S. (2006). Resource use efficiency in Urban Farming: An application of Stochastic Production Function. Int. J. of Agric. and Bio., 8(1), 38-44.

United Nations Development Programme (UNDP). (1996). Urban Agriculture: Food, Jobs and Sustainable Cities. United Nations Development Program, Publication Series for Habitat II, Volume One. UNDP, New York. 